\title{
Incorporação da Tecnologia Digital à Prática Docente: Compreendendo a Gênese Instrumental de Licenciandos em Matemática
}

\author{
Margarete Farias Medeiros - IFC - CAS/PPGIE - UFRGS - \\ margarete.medeiros@ifc.edu.br \\ Marcus Basso - PPGEMAT/IME/UFRGS - PPGIE - mbasso@ufrgs.br
}

\begin{abstract}
Resumo: O presente artigo expõe uma pesquisa, de caráter qualitativo e cunho exploratório, sobre as possíveis causas da resistência de acadêmicos do curso de Licenciatura em Matemática à inserção de Tecnologia Digital (TD) na prática docente. A pesquisa, fundamentada na teoria da gênese instrumental, foi realizada a partir de questionário on-line e observações sobre os comportamentos dos sujeitos durante a realização de propostas didáticas com utilização da TD. A partir da análise dos dados foi possível concluir que existem fortes indícios de que os referidos acadêmicos possuem medo de enfrentarem situações que a TD proporciona em relação aos conceitos matemáticos, que por sua vez, influenciam na resistência à incorporação de tal tecnologia na prática docente.
\end{abstract}

Palavras-Chave: tecnologia digital, resistência, gênese instrumental, formação inicial docente.

\section{Incorporating Digital technology into the teaching Practice: Understanding the instrumental genesis of academics of undergraduate mathematics}

\begin{abstract}
This article presents a research, of qualitative character and exploratory nature, on the possible causes of the resistance of academics of the undergraduate course in mathematics to the use of Digital Technology (DT) in the teaching practice. The research, based on the theory of Instrumental Genesis, was carried out from the online questionnaire and observations on the behaviors of the subjects during the realization of didactic proposals using the DT. There are strong indications that these scholars are afraid to face situations that the DT provides in relation to mathematical concepts, which in turn influences the resistance to the incorporation of such technology in the teaching practice.
\end{abstract}

Keywords: digital technology, endurance, instrumental genesis, teacher training.

\section{Introdução}

A Tecnologia Digital (TD) se apresenta como um importante recurso no ensino e aprendizagem na Educação Matemática (Coll \& Monereo, 2010; Basso \& Gravina, 2012; Basso \& Notare, 2015; Goméz, 2015). Nesse viés, Rock (2017) nos expõe algumas de suas vantagens: seu poder e velocidade computacional; visualização de representação multimídia e dinamismo [Geometria Dinâmica - GD]; acesso à informação e múltiplas formas de comunicação; mobilidade; interação com o usuário; dentre tantas outras. Apesar de tantas vantagens e formas de utilização, encontramos estudos os quais mostram que em muitos casos, quando ela está sendo utilizada, os professores fazem uso dela apenas para visualização [apresentação dos conceitos], cálculos e verificação de resultados (Rock, 2017), não aproveitando dessas vantagens descritas anteriormente. As 
TD permeiam quase todos os aspectos de nossa vida diária (Rock, 2017), porque então não a integrar na prática docente, fazendo com que o aluno possa construir conhecimento matemático por meio dela? Ainda mais que "nossos alunos mudaram radicalmente (...) não são mais as pessoas que o nosso sistema educacional foi projetado para ensinar (...)" (Prensky, 2001, p.1), são "nativos digitais" e estão integrados nessa nova cultura do virtual (Basso \& Gravina, 2012) consequentemente não tendo restrições e nem resistência ao seu uso para construir novos conhecimentos. E nossos professores de Matemática, imigrantes digitais, aqueles que não nasceram no mundo digital? E nossos licenciandos em Matemática? Podemos considerar que a maioria deles nasceu no final do século 20, sendo que nesta época a inserção da tecnologia em sala de aula ganhava força. E porque então encontramos certa resistência à incorporação da tecnologia digital na prática docente? Esta resistência pode ser à relação integração tecnologia digital- Matemática [domínio da tecnologia e dos conceitos matemáticos]?

É nesse viés que buscamos respostas à resistência ao seu uso, fazemos um estudo sobre as possíveis causas da resistência de acadêmicos do curso de Licenciatura em Matemática à utilização da tecnologia digital na prática docente, fundamentados na teoria da gênese instrumental de Rabardel (1995), a partir de questionário on-line e observações sobre os comportamentos dos sujeitos durante a realização de propostas didáticas com utilização da TD

\section{Fundamentos Teóricos}

Estudo recente (Muñoz et al, 2016) trata da tecno-ansiedade [ansiedade informática] como uma das possíveis causas para a resistência à utilização da TD na prática docente. Os autores afirmam que a tecno-ansiedade é uma ativação fisiológica desagradável e desconforto devido ao uso atual ou futuro da TD por professores. Os autores fizeram um estudo para reduzir a tecno-ansiedade em professores [investigaram professores imigrantes digitais atuando com alunos nativos digitais] reduzindo a tecnoansiedade por meio de treinamento específico para lidar com resolução de problemas tecnológicos. De acordo com Muñoz et al (2016) existem muitos estudos afirmando que os professores não têm atitudes positivas em relação aos computadores: porque temem usá-los nas aulas e que não sentem-se preparados para integrar esta tecnologia (Hardy, 1999); têm baixa confiança na integração da tecnologia em sala de aula (BECTA, 2004); estão preocupados em mostrar aos seus alunos que têm competência tecnológica (Larner \& Timberlake,1995); que os alunos esperam que os professores sejam especialistas no uso de tecnologia (Guha, 2000). Além disso, Munõz et al (2016) afirmam que existem estudos os quais relataram que os professores sofrem de ansiedade informática, ou seja, também chamada de tecno-ansiedade. Afirmam ainda fundamentados em (FernandezCruz \& Fernandez-Diaz, 2016) que o uso de TIC (Tecnologia de Informação e Comunicação) cria situações em que os professores nem sempre possuem as habilidades necessárias para lidar com elas. Assim, os professores não podem ajudar os alunos a desenvolvê-las, pois não as possuem.

Howard (2013) nos aponta que as decisões para integrar a tecnologia no ensino são influenciadas por respostas afetivas negativas à tecnologia, aversão geral ao risco no ensino e o valor percebido da tecnologia no ensino [concepção do professor em relação ao uso]. Scherer (1989, apud Jaques \& Vicari, 2005) afirma que as emoções negativas indicam a aversão ou dor e promovem reações de evitar a situação. Diante de tais afirmações temos como hipótese de que o medo pode ser uma das possíveis causas da não integração da tecnologia digital na prática docente por parte dos acadêmicos de 
licenciatura em Matemática. E o que causa essas emoções negativas? A partir de tais reflexões, buscamos na teoria da gênese instrumental, apoio para investigar as possíveis causas dessa resistência.

$\mathrm{Na}$ vida diária estamos imersos em tecnologia digital, quer seja nas atividades do lazer ou mesmo em atividades profissionais. No lazer observamos que pessoas se utilizam de ambientes digitais para trocar ideias, fotos, vídeos, dentre outras atividades, em ambientes tais como o Facebook, Instagram e Youtube. Além disso, a maioria dessas pessoas utiliza-se de aparelhos celulares, os quais hoje proporcionam uma grande variedade de ferramentas como os Apps que facilitam atividades de lazer, controle de contas bancárias, dentre tantos outros serviços. Podemos afirmar que estas atividades estão associadas à ideia de Rabardel (1995) de gênese instrumental pessoal? Também observamos que em diversas atividades profissionais essa tecnologia está facilitando o trabalho. E na área da Educação, mais precisamente na área da Educação Matemática? Como os professores de Matemática estão utilizando-se dessa tecnologia que está disponível? Existe uma grande variedade de softwares e sites, ambientes virtuais de aprendizagem, além de internet com grandes opções de uso. Podemos associar estas atividades à gênese instrumental profissional?

Vamos fazer um breve estudo sobre esta teoria e procuraremos responder estas questões enunciadas anteriormente.

Segundo Abar (2017, p.39), a gênese instrumental de Rabardel "é o processo de transformação progressiva do artefato em instrumento". Rabardel (1995, p.47) considera que o instrumento é "uma entidade mista formada de um artefato e um esquema" (trad.nossa). Sendo que o artefato pode ser material ou não, este sendo produzido para o sujeito (Abar, 2017) e os esquemas construídos pelo próprio sujeito na interação com o artefato. É na gênese instrumental que a relação entre o artefato e o esquema se estabelece e é caracterizada por duas dimensões: a instrumentação e a instrumentalização (Trouche, 2015). Na Figura 1 temos a representação dessas duas dimensões, a instrumentação orientada para o sujeito (tendo relação ao surgimento e evolução de esquemas de utilização e da ação instrumental) e a instrumentalização orientada para o artefato (tem relação com enriquecimento das propriedades do artefato).

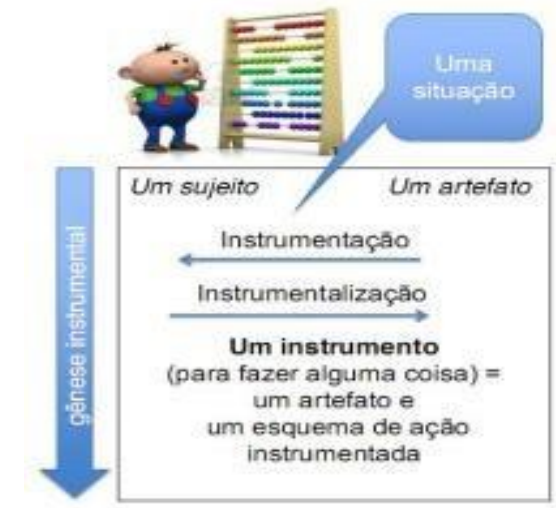

Figura 1: Instrumentação e Instrumentalização Fonte: Trouche (2015)

Para Rabardel (1995, p.52) existe uma tríade nesta transformação de artefato em instrumento: o sujeito, o instrumento e o objeto. Na Figura 2, Rabardel (1995, p, 53) propõe o modelo Situations d'Activités Instrumentées (S.A. I): “com este modelo ternário mostramos a multiplicidade e complexidade de relações e as interações entre os diferentes polos (...)" (Trad.nossa): o sujeito, o instrumento e o objeto. 


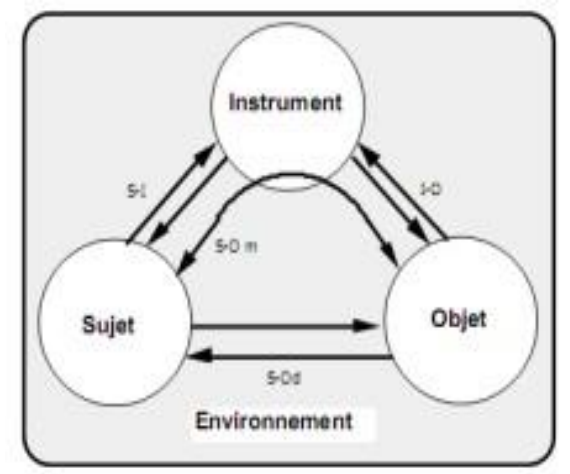

Figura 2: Modelo S.A.I.

Fonte: Rabardel (1995, p.53)

Nessa seção, inicialmente, tratamos de exemplos de situações que relacionam sujeitos [pessoas] com ambientes virtuais [Facebook, Instagram, ...], sendo que existe uma interação entre os sujeitos e esses ambientes, nos quais os sujeitos criam contas e as personalizam de acordo com suas necessidades e interesses. Zuchi (2008, apud ABAR, 2013, p.354) "caracteriza a instrumentalização como um processo pelo qual o sujeito modifica, adapta ou produz novas propriedades, personalizando o artefato de acordo com suas demandas". Neste viés consideramos o artefato [que pode ser material ou não] como sendo este ambiente virtual, e o instrumento, o ambiente virtual juntamente aos esquemas formados pelos usuários nesta interação. Respondemos então, o primeiro questionamento realizado sobre a gênese instrumental pessoal, pois o usuário está tratando de situações ligadas à sua vida pessoal.

E como vamos responder ao segundo questionamento? Nosso interesse está em estudar as atividades relacionadas à formação inicial do professor de Matemática na integração da tecnologia digital à prática docente, e para tanto simularemos uma situação exemplificando a gênese instrumental profissional. Neste sentido consideremos o sujeito [o acadêmico do curso de licenciatura em Matemática] utilizando-se de um software de GD, o GeoGebra [artefato] para o aprendizado de conceitos de geometria plana [objeto]. O sujeito então inicia uma atividade com a construção de um polígono regular [objeto - o hexágono regular] por meio das propriedades da figura hexágono regular. Para a construção do hexágono regular o sujeito necessita de relacionar seus conhecimentos anteriores [esquemas] sobre hexágono regular com as ferramentas disponíveis no software, neste caso inicia-se uma das dimensões tratadas por Rabardel (1995) a instrumentação [orientada para o sujeito], ou seja, as restrições que o software apresenta para a construção da figura em questão. Seguidamente a esta atividade o sujeito já de posse de novos esquemas cria uma ferramenta para a construção do hexágono regular, consideramos aqui que aconteceu a instrumentalização [orientada para o artefato], pois o sujeito personalizou o software de acordo com suas necessidades. De acordo com este exemplo observamos que ocorreu o processo de transformação progressiva do artefato em instrumento, ou seja, a gênese instrumental. Para que ocorra a gênese instrumental profissional, este sujeito deve fazer a integração da tecnologia digital [neste caso desse software] em sua prática docente, proporcionando aos seus alunos que construam o conhecimento matemático. Não basta introduzir o computador, ou os softwares nos ambientes escolares, é necessária a transformação do artefato em instrumento por parte do professor, ou seja, que aconteça a gênese instrumental. Neste sentido concordamos com Rabardel (1995, p.37) que afirma que: "O ponto de vista instrumental em ferramentas cognitivas leva a utilizar a 
tecnologia informática não como um meio de produção ou de soluções recomendadas, mas para ajudar o usuário a alcançar suas próprias decisões." (trad. Nossa).

\section{Resultados e Discussões}

Durante o curso de Licenciatura em Matemática os acadêmicos possuem diversas disciplinas as quais direcionam à utilização de metodologias alternativas para o ensino e aprendizagem da Matemática escolar. Dentre as disciplinas destacamos a Educação Matemática e Tecnologias (EMT), a qual se dedica especificamente ao estudo da utilização de TD na Educação Matemática, pesquisas em Tecnologias Digitais de Informação e Comunicação (TDIC), análise de sites e softwares, sequências didáticas com o uso de TDIC, dentre outros. Neste sentido, consideramos que é proporcionada ao acadêmico uma fundamentação para a utilização da TD em sua prática docente durante o estágio supervisionado. A partir da observação de acadêmicos em aulas do estágio supervisionado percebemos que estes optavam por não utilizar nenhuma TD para desenvolvimento dessas aulas. Em consequência surgiram vários questionamentos: 0 acadêmico possui medo de usar a TD em sala de aula? Podem apresentar a tecnoansiedade? Esse medo tem relação à integração do conhecimento específico da Matemática e a TD? A concepção do uso de TD dos acadêmicos influencia em sua prática docente no estágio? Nesse viés, realizamos um estudo de forma qualitativa e cunho exploratório, a partir do qual buscamos respostas observando os comportamentos de nove acadêmicos da sétima fase do curso de LM, durante a aplicação de uma proposta didática utilizando TD e de questionário on-line respondidos pelos mesmos. $\mathrm{Na}$ análise do referido questionário buscamos a estatística descritiva como apoio.

No ano de 2017, no primeiro semestre, ofertamos a disciplina de EMT e nove acadêmicos frequentaram as aulas, sendo que na disciplina havia uma tarefa que constava da criação de uma sequência didática na qual deveriam integrar a TD. Todos os nove acadêmicos desenvolveram tal tarefa utilizando-se de uma variedade de softwares: três de programação; dois de GD; um de simulação envolvendo conceitos físicos; dois de álgebra; um utilizando-se de um software para construção de mapas conceituais, o qual ele utilizou para tratar de conceitos de análise combinatória.

Observamos que todos os acadêmicos se esforçaram no desenvolvimento da aula, utilizando-se da TD para promover o pensamento matemático. Porém, a partir da observação do comportamento e da forma como eles utilizaram-se da TD, somente três deles, apresentaram indícios de que poderia ter ocorrido a gênese instrumental profissional, ou seja, aquela que se refere à prática docente. Essa afirmação se fundamenta em situações em que a TD promoveu além do que o acadêmico havia preparado. Houve questionamentos por parte dos acadêmicos participantes para o acadêmico palestrante sobre outras formas de se utilizar o software, por exemplo. Perguntas que surgiram e foram respondidas, e situações de restrição da $\mathrm{TD}$, as quais foram apresentadas confirmando que o acadêmico palestrante havia se apropriado da TD.

Para complementar nossa pesquisa elaboramos um questionário em busca de dados que confirmassem as possíveis causas que interferem nesta incorporação da TD. $O$ questionário procurou interrogar sobre o uso de TD, apoiado nos conceitos tratados na fundamentação teórica descrita nesse artigo. Dos nove acadêmicos sete responderam ao questionário [nove questões].

A primeira pergunta foi em relação à gênese instrumental pessoal, isto é, foi perguntado aos acadêmicos se eles integravam a tecnologia digital em sua vida pessoal, 
sendo que todos responderam que sim: no lazer e, em algumas disciplinas do curso para sua aprendizagem. Diante de tais respostas consideramos que não existe resistência à integração da tecnologia digital na vida pessoal, e provavelmente já tenha ocorrido o processo da gênese instrumental pessoal.

Na pergunta seguinte tratamos da gênese instrumental profissional, ou seja, foram arguidos sobre a possível utilização de TD na sua vida profissional [se fossem atuar como professores de Matemática], sendo que três alunos responderam que sim e quatro alunos responderam que "às vezes utilizaria". Verificamos que já houve divergência nas respostas indicando que para utilizar na vida profissional possivelmente existem restrições, reforçando ainda uma ideia de resistência ao uso, pois no nosso entendimento se houver a apropriação da TD, existe uma abertura do sujeito às inovações, ou seja, não haveria restrição ao uso, pois o sujeito teria transformado o artefato em instrumento [gênese instrumental].

Perguntamos também sobre a concepção que eles têm sobre a utilização de TD para o ensino e aprendizagem da Matemática escolar. Das sete respostas encontramos um acadêmico que não soube dizer qual era a sua concepção, nesse sentido refletimos que se um acadêmico não sabe descrever qual é a sua concepção do uso da TD em sala de aula, ele não fará uso dessa tecnologia para construção de conhecimento e, talvez, nem a utilize. Os demais elencaram: a importância da tecnologia digital; seu potencial como facilitador do processo de ensino e aprendizagem da Matemática e que exige planejamento. Destacamos uma das respostas que apresenta indícios sobre restrições do acadêmico ao uso: "Acredito que utilizar tecnologias digitais para ensinar Matemática é muito interessante e enriquecedor, na mesma medida que torna o processo de ensino, para o professor, mais complexo/difícil, uma vez que o aluno consegue fazer várias suposições $\boldsymbol{e}$ questionamentos. Em minha concepção o professor que utiliza alguma tecnologia, antes de saber utilizá-la para o ensino de Matemática, precisa saber Matemática, e muito bem. Além disso, o uso da tecnologia dificilmente, permitirá que a sequêncial planejamento do professor seja cumprida." Nessa fala, observamos a preocupação com o "saber matemática" antes de utilizar a TD. Além disso, também é destacada a ideia de que a TD pode proporcionar situações, as quais não estão previstas, causando desconforto ao professor.

O questionamento a seguir foi em relação ao medo de integração da TD para ensinar Matemática: três alunos responderam que sim e quatro responderam que não. Selecionamos uma resposta que talvez evidencie o porquê do medo: “(...) a tecnologia permite ao aluno fazer várias suposições, muitas vezes não consideradas pelo professor (...)". Trazemos aqui a ideia de que podem acontecer situações inesperadas, ou seja, o software permite que o aluno vá além da atividade prevista pelo professor e isso pode ser um indício de resistência, de não estar preparado para enfrentar tais situações. Quanto a possuírem a tecno-ansiedade, somente um acadêmico respondeu que sim, e outro afirmou que: (...) "talvez sinta desconforto ao utilizar tais recursos, mas considero normal (...)". Cinco acadêmicos consideram que não possuem tecno-ansiedade. Isso nos leva a considerar que talvez não a possuam por estarem integrados à tecnologia digital na vida pessoal [gênese instrumental pessoal].

Em relação à questão: "Existem muitos estudos afirmando que os professores não têm atitudes positivas em relação aos computadores: porque temem usá-los nas aulas e que não sentem-se preparados para integrar esta tecnologia; têm baixa confiança na integração da tecnologia em sala de aula; estão preocupados em mostrar aos seus alunos que têm competência tecnológica; que os alunos esperam que os professores sejam 
especialistas no uso de tecnologia. Você possui algumas destas atitudes? Se sim, quais?" Os acadêmicos evidenciaram a preocupação de mostrar aos seus alunos que sejam especialistas no uso de tecnologia e novamente apareceu a preocupação de um imprevisto sobre conceitos, ou seja, na abertura que os softwares, por exemplo, proporcionam aos alunos conjecturarem e irem além do que foi planejado pelo professor.

Na oitava questão tratamos da resistência ao uso: "Howard (2013) nos aponta que as decisões para integrar a tecnologia no ensino são influenciadas por respostas afetivas negativas à tecnologia, aversão geral ao risco no ensino e o valor percebido da tecnologia no ensino [concepção do professor em relação ao uso]. Você apresenta algumas destas características? Se sim, quais?" Dos sete acadêmicos três apresentaram que sim e quatro não. Destacamos uma resposta que talvez nos ajude a esclarecer a resistência: "Sim, a princípio tinha aversão ao uso de tecnologias na sala de aula, entretanto, com algumas disciplinas do curso pude perceber que é importante além de necessário, dado o meio em que estamos/estaremos inseridos." Evidenciamos que existe resistência para ensinar com uso de TD, mas que como hoje estamos imersos em tecnologia digital isso nos leva a crer que estarmos em constante evolução e adaptação às mudanças, sendo que a utilização na disciplina poderia ocorrer. Nesse viés percebemos que se houver a incorporação da TD, a gênese instrumental, esse acadêmico estará utilizando tal tecnologia em sua prática como docente.

Para finalizar o questionamento nós perguntamos sobre qual a concepção que eles têm sobre um professor que não utiliza TD para ensinar a Matemática escolar. Um acadêmico não soube responder; outro afirmou que este professor estaria "defasado"; outro afirmou ser "difícil avaliar, pois são muitas coisas que interferem na sua prática"; dois destacaram que talvez este professor não tenha tido em sua formação disciplinas que oportunizassem a competência tecnológica; outro afirmou que é melhor uma aula "tradicional bem dada" do que uma aula com o uso de tecnologia digital sem objetivos de construção de conhecimento matemático. Verificamos neste caso, que existem divergências de ideias em se tratando de avaliar se um professor utiliza TD na sua prática docente. Ao nosso ver, eles não têm uma concepção estruturada e nem argumentação suficiente para defender o uso em sua prática docente; nos pareceu um pensamento, de certa forma, "frágil" sobre a inserção da TD em sala de aula.

\section{Considerações Finais}

Diante dos comportamentos observados dos nove acadêmicos durante a prática com inserção de TD na proposta didática e em relação às respostas ao questionário online, fundamentados na teoria da gênese instrumental, consideramos que a maioria dos acadêmicos possui restrição ao uso na prática docente. E porque encontramos resistência à integração da tecnologia digital na prática docente? Esta resistência pode ser à relação integração tecnologia digital- Matemática [domínio da tecnologia e dos conceitos matemáticos]?

Lançamo-nos em busca das possíveis causas para essa resistência e nos servimos de fundamentações na teoria da gênese instrumental pessoal e profissional e tecnoansiedade [ansiedade informática]. Ao nosso ver, somente três, dentre os nove acadêmicos conseguiram transformar o artefato em instrumento em sua atuação como docente. De acordo com nosso estudo, evidenciamos que os acadêmicos estão integrados em TD na vida pessoal, mas que existe resistência para integrá-la na prática docente, e que talvez esta resistência esteja imbricada na relação domínio da tecnologia e conceitos 
matemáticos, no que tange a possibilidade dada pela tecnologia ao aluno ir além dos conceitos tratados e colocar o professor em cheque [essa afirmação foi fundamentada nas respostas obtidas por meio do questionário on-line direcionado aos nove acadêmicos e seus respectivos comportamentos enquanto a utilizavam]. Com a incerteza do que poderá acontecer existe o medo de não conseguir esclarecer as dúvidas criadas pelos alunos. E isso pode ser um dos fatores que causam o medo para a inserção da TD em sala de aula. Neste sentido a Computação Afetiva ${ }^{1}$ poderá, talvez, nos ajudar, por meio do uso de sensores que detectem essas emoções e façam medições, enquanto o acadêmico executa sua atividade docente. Neste viés lançamos esta ideia para utilizarmos em trabalhos futuros.

Nosso presente estudo também pode nos levar a concluir de que a tecno-ansiedade não seja um dos fatores que contribuem nesse processo de resistência, visto que os acadêmicos estão integrados tecnologicamente na vida pessoal. Esse trabalho tem limitações, primeiro que temos um número baixo de participantes [sete responderam ao questionário], e talvez se tivéssemos um número maior poderíamos ter resultados mais conclusivos. Também porque estamos observando depoimentos, que talvez não reflita exatamente o que o acadêmico sente, neste caso a ideia de utilizarmos sensores para medição da emoção em trabalhos futuros.

\section{Referências}

ABAR, Celina Aparecida A. P.. Tecnologias Digitais e Educação Matemática. In: Congresso Uruguayo De Educación Matemática, 7, 2017, Montevideo. Actas. Montevideo: Curem, 2017. p. 33 - 41.

BASSO, Marcus; GRAVINA, Maria Alice. Mídias Digitais Na Educação Matemática. In: GRAVINA, Maria Alice et al (Org.). Matemática, Midias Digitais E Didática: Tripé Para A Formação Do Professor De Matemática. Porto Alegre: Evangraf, 2012. Cap. 1. p. 11-35.

BASSO, Marcus; NOTARE, Marcia R.. Pensar com tecnologias digitais de matemática dinâmica. Renote: Revista Novas Tecnologias na Educação, Porto Alegre, v. 2, n. 13, p.01-10, dez. 2015.

BECTA. A Review of the Research Literature on Barriers to the Uptake of Ict by Teachers. British Educational Communications and Technology Agency, 2004. Disponível em: < http://dera.ioe.ac.uk/1603/1/becta_2004_barrierstouptake_litrev.pdf> Acesso em: 05 mar.2017

COLL, Cesar; MONEREO, Carles. Psicologia da educação virtual: aprender e ensinar com as tecnologias da informação e da comunicação. Porto Alegre: Artmed, 2010

FERNÁNDEZ-CRUZ, Francisco-josé; FERNÁNDEZ-DÍAZ, María-josé. Generation Z's Teachers and their Digital Skills. Comunicar, [s.1.], v. 24, n. 46, p.97-105, 1 jan. 2016.

\footnotetext{
${ }^{1}$ Termo cunhado por Picard (1997). 
GÓMEZ, Angel I. Perez. Educação na Era Digital: A Escola Educativa. Porto Alegre: Artmed, 2015.

GUHA, S. Are we all Technically Prepared? Teachers Perspectives on the Causes of Comfort or Discomfort in Using Computers at Elementary Grade Teaching. In: National Association for the Education of Young Children, 2000, Atlanta. p. 1-48. Disponível em: < https://files.eric.ed.gov/fulltext/ED456101.pdf> Acesso em: 23. Abr. 2017

HARDY, Janice V.. Teacher Attitudes Toward and Knowledge of Computer Technology. Computers In The Schools, [s.1.], v. 14, n. 3-4, p.119-136, 8 jan. 1999.

HOWARD, Sarah K.. Risk-aversion: understanding teachers' resistance to technology integration. Technology, Pedagogy And Education, [s.1.], v. 22, n. 3, p.357-372, out. 2013.

JAQUES, Patrícia Augustin; VICARI, Rosa Maria. Estado da Arte em Ambientes Inteligentes de Aprendizagem que Consideram a Afetividade do Aluno. Informática na Educação. UFRGS: Porto Alegre, v. 8, n. 1, p. 15-38, 2005.

LARNER, D.; TIMBERLAKE L.. Teachers with Limited Computer Knowledge: Variables Affecting Use and Hints toIncrease Use. Curry School of Education, University of Virginia, 1995, p.1-65. Disponível em: < https://files.eric.ed.gov/fulltext/ED384595.pdf> Acesso em: 23 Abr. 2017.

MUÑOZ, Olga Revilla et al. Reducing techno-anxiety in high school teachers by improving their ICT problem-solving skills. Behaviour \& Information Technology, [s.1.], v. 36, n. 3, p.255-268, 7 set. 2016.

PICARD, R. Affective Computing. Cambridge, Massachusetts: MIT, 1997.

PRENSKY, Marc. Digital Natives, Digital Immigrants Part 1. On The Horizon, [s.1.], v. 9, n. 5, p.1-6, set. 2001.

RABARDEL, P. Les hommes et les technologies: une approche cognitive des instruments contemporains. Paris: Armand Colin, 1995. Disponível em: < https://hal.archivesouvertes.fr/file/index/docid/1017462/filename/Hommes_et_technologie_Rabardel1995. pdf>. Acesso em: 24 Mar. 2017.

ROCK, Ana Isabel Sacristán. Aprender Matemáticas en la Era Digital. Avance y Perspectiva. México, Cinvestav, V.2. n.4, 2017.

TROUCHE, L. Dos artefatos aos instrumentos do trabalho matemático: a dualidade essencial instrumentação-instrumentalização, Escola de Altos Estudos, 2015. 